\title{
Ovarian Cancer and Primary Peritoneal Carcinoma TNM Finding v7
}

National Cancer Institute

\section{Source}

National Cancer Institute. Ovarian Cancer and Primary Peritoneal Carcinoma TNM

Finding v7. NCI Thesaurus. Code C89637.

A finding about one or more characteristics of ovarian cancer or primary peritoneal carcinoma, following the rules of the TNM AJCC v7 classification system. Ovarian cancer and primary peritoneal carcinoma are surgically/pathologically staged malignancies.

(from AJCC 7th Ed.) 